\title{
The new packaged food products containing insects as an ingredient
}

\author{
M. Reverberi \\ Bugsolutely (www.bugsolutely.com), Plento (www.plentofoods.com), 20-19 Sukhumvit soi 39, Bangkok 10110, Thailand; \\ massimo.reve@gmail.com
}

Received: 31 August 2020/ Accepted: 12 November 2020

(c) 2021 Wageningen Academic Publishers

OPEN ACCESS @)@(1) RESEARCH ARTICLE

\begin{abstract}
This article focuses on a newly defined category of insect as food: packaged processed insects (PPIs). PPIs integrate dry insects (in pieces or in powder) in packaged food products such as snacks, pasta, or baked goods. PPIs have been on the market for a few years, and they are still far from being mainstream. The commercial challenges they face, all of which are addressed in this article, include production costs, certifications and regulations, marketing communication, and retail distribution and consumer targeting. The western preconception of insect eating, which has been extensively covered in the existing literature, is also taken into account, but from the food makers' angle: how to deal with it when selling PPIs. Eleven PPI makers have contributed to this article by agreeing to a standardised interview protocol about their PPI products. Their names and a summary of the information collected is found in Supplementary material S1.
\end{abstract}

Keywords: packaged processed insect products (PPIs), edible insect products, cricket flour, insect food development

\section{Introduction}

This article proposes a fundamental conceptual distinction: that the traditional, culturally-sanctioned practice of eating whole insects is a categorically different notion from the more recent use of mainly farmed insects as processed ingredients in packaged foods.

Traditional entomophagy mostly relates to the local consumption of whole insects collected from the wild and is found mostly in non-Western countries. In contrast, the practice which for brevity we will call packaged processed insects (PPI), is taking place on a light-industrial scale, largely in Western countries. PPIs use ingredients made from farmed insects (usually mealworm flour or cricket flour) to create foods such as crackers, pasta, energy bars, and snacks, as well as burgers and meatballs.

PPIs differ from traditional entomophagy for other reasons, too. One is consumer motivation: Traditional insect consumption is often driven by taste preferences within an informal economy. But PPI's key selling points also include the consumer's perception of the virtues of sustainability and nutrition.
Distribution and production channels are different, too. PPIs require at least two steps: both the farming and processing of the insect-based ingredients. In some cases one more intermediate step, the cricket-flour making, is performed by a company which buys the crickets from farmers, processes them into flour, and sells it as an ingredient it to food manufacturers.

The need to distinguish between whole insects and processed insects as an ingredient has been raised in very recent years, after considering the differences between the two categories (Orsi et al., 2019). A study of European startup websites has noted how narrow the processed packaged food category is (Pippinato et al., 2020).

PPIs are a very new food category, with almost all processedinsect products appearing on the market in the past ten years. Among the pioneers are cricket-flour items such as cookies by Bitty Food (USA), chips by Six Foods (USA), meatballs and schnitzel by Damhert (Belgium), and cricket pasta by Bugsolutely (Thailand). Aldento (Belgium) offers a mealworm pasta, and in 2016 the Canadian start-up One Hop Kitchen launched pasta sauces containing mealworms and crickets. 
Cricket flour has been used extensively in energy bars, with more than 20 USA and European brands (Reverberi, 2020a). Most of these bars contain a small percentage of cricket flour (5 to $10 \%$ ), presumably to maintain a low retail price in view of the high cost of cricket flour in the USA and Europe. Recent trends have raised the percentage to 10 to $15 \%$ in new products, with peaks at $20 \%$, with the result of more evident nutritional advantages. Depending on the food category, there might be limits to increasing the insect powder percentage due to taste, texture and binding issues. North American insect-food makers seem to believe that crickets are the best choice in terms of customer acceptance, while in Europe a growing number of start-ups are choosing mealworm powder for their new products (possibly as a result of the lower cost of mealworm powder compared to cricket powder).

In this article 'insect powder' and 'insect flour' are considered synonyms. Most PPI producers working with processed farmed insects call the resulting ingredient 'insect flour', while a minority refers to it as 'insect powder'. Some experts dispute the use of the term 'flour' (Dossey, 2016) arguing that flours are made from vegetable, not animal, sources. Still, for a marketing usage, the word flour may resonate better with consumers.

\section{Methodology}

PPI makers were selected from the public list on the blog BugBurger (www.bugburger.se), known for containing a large number of insect start-ups (more than 300, including specialised retailers and farms), and which is frequently updated. The author of the list provided his suggestions for the selection.

Eleven start-ups have been selected among 70 PPI makers, using criteria that focused on those with an innovative product, and which reflected different food categories (e.g. snacks, energy bars, burgers, crackers, etc.).

The selected PPI entities were then sent a questionnaire consisting of 10 standardised questions. Three of the 11 interviews were conducted by email, with the 8 others interviews conducted as teleconferences, which allowed for a more open conversation and exchange of ideas. Although the interviewees were generally reluctant to disclose turnover or sales data, they freely answered questions about their distribution channels and retail strategy, which greatly assisted the understanding the commercial aspects of PPIs.

One product (Bug Recipes), a home-cooking subscription box which includes whole insects, does not completely fit the methodological definition of PPI but was considered relevant, since the promotion of insects in food through home-cooking is new and interesting.

\section{Targeting consumers and selling points}

Since the early years of their emergence (2014-2018), PPIs faced the dilemma of trying to go mainstream or aim at a market niche. According to the PPI makers interviewed, PPIs have the potential to be a mass market product. However, bias against eating insects, high prices due to small-scale production, and other obstacles novelty foods usually come across may work against the ambition of targeting the full spectrum of consumers. The most commonly selected consumer groups to start with are people with a high degree of appeal for diet, fitness, health and sustainability. One of the interviewees mentioned 'flexitarians' (those who rarely eat meat, and believe in a semi-vegetarian diet with a touch of 'flexibility') as a very promising target group. Vegetarians were also seen as a target group by most of the start-ups, too. The three key reasons influencing consumers towards a vegetarian diet are: promoting sustainability, reducing animal suffering and eating healthier food (Ruby, 2012). PPIs makers often make the same arguments for eating their products.

A similar demographic is described as "lifestyles of health and sustainability', a particular market segment related to sustainable living, and generally composed of a relatively upscale and well-educated population segment. Another large target group is comprised of 'foodies', i.e. people looking for new food experiences. In terms of consumer age, the range $20-40$ is often cited by PPI makers. While there is little literature on the socio-demographic profile of potential Western edible insect consumers, higher education seems to be an important factor (Cicatiello et al., 2016). This may be connected with elevated awareness of the nutritional and environmental benefits of insect eating. Gender seems to have some relevance, too, with males slightly more inclined to try insect food (Verbeke, 2014; Wendin, 2017). Age is also related to edible insect consumption, and there are indicators suggesting younger people should be targeted more than people above their 40s (Videbaek, 2020).

In terms of what to communicate to the target, the PPI makers surveyed for this article classified taste as the key factor. In food, taste ranks as the top buyer's driver (IFIC Foundation, 2019), and without being delicious, a product has little chance of generating repeated sales.

Nutrition is usually considered the second key point helping generate sales. While taste is subjective, and most consumers are unlikely to be swayed to buy a product by a bald claim that it's 'yummy!', a food's nutritional value is an objective fact. PPIs high in proteins, minerals or vitamins can leverage these nutritional benefits as selling points.

Four of the PPI makers interviewed emphasised that environmental concerns are becoming more important 
to their customers. This is confirmed in a market research study (Nielsen, 2019) which reveals a clear consumer trend toward sustainability in food products. Thanks to the vast media coverage on edible insects in the past five years, most consumers perceive of PPIs as an environmentally friendly product. The sustainability of farmed crickets as food has been investigated (Halloran et al., 2017) and confirmed, although little similar research is available about the sustainability for farmed insects like mealworms and silkworms.

\section{Packaging and consumer trust}

The image of eating whole insects can trigger negative emotions in Western consumers, according to a number of surveys and authors (for example, Collins, 2019). This is likely the reason why most PPI packaging does not display photos of insects (although logos and package labels sometimes contain stylised drawings of insects).

Obtaining consumer trust is a critical point with PPIs (Lensvelt, 2014), especially as Western consumers often associate insects with pests and diseases (Orsi et al., 2019; Van Huis et al., 2013), paying little mind to whether the insects were farmed and processed in a safe plant. From this perspective, modern, well designed industrial packaging would generate more confidence than the paper bags that have been used (and are still in use) in some PPI packaging. Paper bags are obviously a cheaper option for small-scale productions, and are frequently used with natural, organic food products, but given the negative perceptions about eating insects, the adoption of packaging aligned with other mass-market consumer products might foster the consumer perception of PPI as a 'normal' product made in a certified, standardised factory. PPI pioneers like Exo or Chirps followed this approach, and changed packaging a number of times to make the product look more mainstream. They also made very clear it is an insect-based product. Conversely, any attempt to hide the insect ingredient - for example, by naming it 'alternative protein' - could backfire in terms of consumer trust, if it is perceived as an attempt to disguise an unhealthy or unsavoury ingredient. In brief, the best approach to market an insect ingredient may be to be clear about the insect content, but with the text, not visually.

\section{Protein source or superfood?}

In the period 2015-2020, cricket energy bars have been the most common choice among makers of PPIs. Targeting the fitness niche with an alternative protein makes sense as a market strategy, but also results in competing in an established, very competitive market where customers are often aware of nutritional facts and the comparative value for money when looking for protein. When compared with commoditised sources of protein like whey, insects might be too expensive to appeal to consumers. The expression 'insect protein' is quite common, but it may undermine the potential of PPIs as a 'superfood' containing other nutritional benefits.

There is no legal barrier in using the word 'superfood' to describe PPIs (Schiemer et al., 2018). Claims on the product packaging are subject to regulatory restrictions in many countries, but the word 'superfood' may still be used when communicating to the market and the media.

\section{PPIs are not 'survival food'}

While PPIs seem to have reached higher consumer acceptance in Western countries, the consumption of whole insects is still more likely to trigger a negative emotional reaction within the consumer audience (Videbaek et al., 2020; Wendin et al., 2017). In the popular imagination, insects are considered as a 'last-resort' food source to be consumed only during periods of food insecurity. Indeed, popular entertainment has perpetuated this idea, with reality TV shows like 'Man vs. Wild' depicting insect consumption as a near desperate alternative to starvation. Similarly, the post-apocalyptic blockbuster movie and TV series 'Snowpiercer' depicts an underclass being force-fed distasteful insect-based foods.

Despite these popular distortions and biases, it is true that entomophagy is a valid solution to food insecurity. Collecting or farming insects in poor countries represents a common practice in many countries and a very interesting opportunity as a protein source. Many initiatives are in place to develop this approach to eating insects, for example the Dutch-Kenyan-Ugandan initiative called the Flying Food project, or the LAO project 'Improving Livelihoods and Food Security in Laos and Cambodia' (Weigel et al., 2018).

But the perception of insects as a last-resort survival food represents a challenge to convincing Western consumers to eat PPIs. This aversion appears to be deeply rooted: most Westerners seem to show this bias before they ever encounter or taste insect-based foods. And it is interesting to note that the bias may be increasing even in countries where eating insects has been a tradition. Modernisation, globalisation and westernisation may have a key role in changes regarding entomophagy (Muller, 2019).

Marketers of PPIs should therefore try to counter this perception by focusing on concepts like taste, nutrition and sustainability. In brief, PPIs should be presented as a positive choice, not as a necessity, and reject the image of insect eating as 'primitive people's practice' (Verbeke, 2014). 


\section{Allergy and COVID-19 from a marketing perspective}

Despite the widespread usage of crickets as human food, cases of food allergy to crickets are relatively rare (Pener, 2016). Most of the PPI products have an allergen alert on the label, which is also a requirement by the US Food and Drug Administration (FDA). From a business perspective, the risk of consumers suffering allergic reactions to PPIs, and the likely huge media backlash that would follow, cannot be dismissed. Although edible insects have thus far proven to be an appealing narrative for the media, given the Western public's underlying bias against eating insects, a deadly outcome of an allergic reaction could trigger wide media coverage, and possibly negative consequences on the market growth of PPIs.

According to research by Dicke et al. (2020), the hazard of edible insects being a transmission vector of COVID-19 is extremely low. This finding is very important from a business perspective: edible insects are already the target of some consumer fears, and any perceived connection to the global pandemic would exponentially magnify those emotional negative reactions. It will be crucial for insect start-ups to communicate to the market that certified insect products are as safe, if not even safer, than other animalbased food.

\section{The difficulty of knowing the size of the market}

At least five market surveys with economical data have been published in the past few years, from Meticulous Research, Global Market Inside, Persistence Market Research, Arcluster and Credence Research. All the projections predict strong growth in edible insects in the next ten to twenty years. However, there are a number of reasons to question the validity of these data. First, traditional entomophagy is mostly a local countryside tradition, with insects collected from the wild or in very few cases raised in small scale-farms and consumed locally, for example as a street food or shared within a village. Even in countries like Thailand, where farming crickets has turned into a profitable side business for thousands of farmers (Hanboonsong et al., 2013), the market still relies on an informal distribution in food markets where no receipts or invoices are ever released. The possibility to track traditional insects eating is close to impossible via official sales records.

When it comes to international commerce of insect flours, there are few ways to accurately calculate the size of the market, because the World Customs Organization (WCO) has not yet created any code for edible insects. These codes, known as harmonised system, are used internationally to categorise goods and apply duties, and it takes years to the WCO to release an update when new product categories appear. Further complicating the valuation of the PPI market, PPI products are often sold directly from manufacturers through their online shops and shipped individually, which makes it difficult to gather reliable data on overall market sales.

Given these barriers to accurate measurement, one should be wary of predictions such as the recent forecast that 'the global edible insects market is expected to reach USD 7.96 billion by 2030' (Meticulous Research, 2019). It is almost impossible at present to collect accurate data on the insectbased foods market at the level of consumer sales.

When considering Europe only, where insects are farmed and processed in a certified and controlled environment, it is possible to have more reliable market data, at least on the quantity of food-grade cricket and mealworm powder produced. According to a survey of 33 companies conducted by the International Platform of Insects for Food and Feed (IPIFF), the EU non-profit organisation focusing on insects for food and feed (IPIFF, 2020), consumption of PPI and whole-insect foods in 2019 totalled an estimated 500 tons. In the food industry, that is a negligible amount, corresponding to a dozen shipping containers.

Only a few food-grade insect farms (Entomo Farm, Aspire Food Group, Protifarm) have reached a post-seed-start-up status. According to data from Linkedin, Aspire's staffing level is almost 60 and the last funding they received in a Series A round was 7.3 million USD. Entomo Farm affirms they have 35 million crickets growing at any time in their 2,000 $\mathrm{m}^{2}$ farm (Canadian Food Business, 2020). Protifarm, the largest European insect for food farm, has already reached the Series B with investors pouring in the company more than 10 million USD (Pothering, 2019). But dozens of other farms are much smaller, which is also the case for PPI makers.

In terms of staff, the companies interviewed for this article have an average of 5 full time employees, including the founders. The interview with the PPI representative for Micarna revealed that even through the parent company has a workforce of 3,400, only three employees are focused on edible insects. The survey by IPIFF (IPIFF, 2020) of 33 European edible insect companies reported that $81 \%$ of them are micro-companies with less than 10 employees.

Between 2014 and 2018 there had been a few attempts to create reliable databases of new edible-insect companies (those not belonging to traditional entomophagic cultures and mostly located in Western countries). Among these efforts two were notables: the Bugs Feed website, developed in conjunction with the launch of the Danish documentary 'Bugs', and the Maggot Master database created by Ilkka Tapponen, now converted into a Wiki page with around 400 
entities. Both lists appear to be inactive now, although still useful for research purposes. The list handled by Anders Engstrom at www.bugburger.se seems to be the best option to get a real-time picture of the edible insect business at the moment, and it contains 320 entries. About half of these may fall into the PPI or the 'whole packaged insects' categories, while the others are farmers/processors and retailers specialising in edible insects, plus a few bug restaurants. According to Engstrom (who provided suggestions for this article), the mortality rate of the insect-based food start-ups is high, and while it is easy to find new entities when they launch a product, it is much harder to know when they cease activities. There are many recent examples of small scale businesses whose scarce sales resulted in failure after a couple of years, including One Hop Kitchen (Canada), Mophagy (UK), and Lithic Nutrition (USA).

\section{The challenge of entering supermarkets}

Start-up-made novelty foods often hit the market through online shops, because of the lower cost and relative simplicity of e-commerce. But PPIs still need to win consumer trust, with one important avenue being exposure on the shelves of supermarkets or corner shops. These traditional food retailers expect products to sell quickly, which might be a challenge as the PPI market ramps up. But obtaining such shelf exposure will undoubtably improve consumers' emotional confidence in PPIs. Consumers need to touch the physical product and read its label claims and facts, and they tend to trust a supermarket chain more than an online shop. Until PPIs are widely distributed in normal retail points of purchase, consumers will not fully embrace it as credible and safe.

The companies interviewed here confirmed that PPIs perform better through physical retailers than through e-commerce. In the early stages (between 2015 and 2018), start-ups focused on e-commerce to reduce distribution and retail costs, but now PPIs makers, particularly those in the European Union, are often targeting supermarket chains. A few European supermarkets are testing the products in some stores. It is the case with Sainsbury's (UK), Irma (Denmark), Metro (Germany), Coop (Switzerland), Rewe (Germany). Some start-ups also reported exploring alternative and easily approachable channels, such as specialised organic and novelty-food shops, food trucks and food services. Organic shops seemed a particularly good fit for the PPI customer profile, but it is hard to get an organic certification for PPI products. In the case of crickets, farms are struggling to find the organic cricket feed needed to have a complete organic rearing process. Furthermore, their business is often too small to make the cost of an organic certification feasible.

Access to supermarket chains is also harder if PPIs do not have industrial certifications like ISO or BRC. Using a reliable co-packer (third party) for the production of the PPI often ensures a reasonable level of food safety standards.

\section{Product development, production cost and retail price}

Start-ups have two options for product design: make the prototype in a professional kitchen or engage an R\&D centre. Shared kitchens are becoming a popular way to develop recipes, an option that is viable for simple products like bread or an energy bar, but less feasible if the product needs machinery like an extruder or a vacuum fryer. Expensive large industrial machines can be found in copacker facilities, and the co-packer might be willing to test the product formulation in the factory.

Universities often work for private companies in product development. For example, Plento (www.plentofoods. com) outsourced the development of an insect snack to the Singaporean Polytechnic's Food Innovation Research Center. R\&D can be performed also by private specialised centres. Although this solution can be a major financial commitment for a start-up, it secures a methodological approach and expertise which is not always available within the start-up team.

When it comes to setting the product price, consumers who are early adopters usually accept to pay a premium price for innovation, nutrition and sustainability, but only to a certain point. And PPI products are often quite expensive. Where does the premium price of PPI products come from?

First, small companies are confronted with higher costs of running small production batches. Small volumes means copackers will charge the start-ups more for the production.

If the PPI is meant for export, either informally through basic postal services, or officially with a proper export operation, the product price can easily double because of shipment and/or custom fees. The custom and freight fees of an international cargo, even when as small as half a ton (just a couple of pallets or cubic meters) exceed 1000 USD, and the final product price will be highly affected.

The insect ingredient cost is also critical, of course. Despite insect powder farmers and processors are scaling up production and lowering the insect flour price every year, insects are still an expensive ingredient. At the dawn of PPIs, around 2015, the North American cricket flour wholesale price was close to $100 \mathrm{USD} / \mathrm{kg}$ and in Thailand was averaging 30 USD/kg. In 2020 it is below 40 USD/ $\mathrm{kg}$ in North America and below $20 \mathrm{USD} / \mathrm{kg}$ in Thailand. Western farms like Entomo (Canada), Aspire Food (USA) and Protifarm (the Netherlands) are testing automation and vertical farming to reduce the cost of labour, while Thailand's estimated 7.5 tonnes per year production 
(Hanboonsong, 2013) is largely based on small, family farms, with very low operating costs, but also low productivity. It is yet to be seen what insect-farming approach will prevail between the Thai model of Small Scale Livestock Farm (as defined by Halloran et al., 2018) and Western-model factory farming. European cricket flour is even more expensive (between 60 and 90 USD/kg) than the North American one but they offer a more reasonable price for mealworm flour and dry whole mealworms (around 25 USD/kg), arguably one of the reasons for the growth of European PPIs made with mealworms. The insect price largely determines the choice of insect percentage in PPIs, which averaged between 6 and $12 \%$ five years ago, and is growing every year with a number of PPIs featuring 15 to $20 \%$ insect content in 2020. The PPI makers interviewed reported a typical percentage of 10 to $20 \%$, with two exceptions (one product with $5 \%$, and another with $30 \%$ ).

\section{Production, certification and regulations}

A contract packager, commonly called a co-packer or an OEM, is a manufacturer that will produce, package, and/ or label a product for clients. A co-packer is often a factory that not only manufactures its own products, but also makes private-label products for other companies. In addition to manufacturing, packaging, and labelling, co-packers also offer start-ups the benefit of certifications as well as other services like storage and shipping (O’Donoughue, 2020). The advantages for a start-up with limited resources and a concept still to prove are evident, and this is the most common option chosen by consumer-product start-ups in the early stages of their companies. The PPI makers interviewed confirmed this approach: 8 out of 10 are using a co-packer.

In terms of food safety international standards, HACCP is the most common certification adopted by insect flour processors and normally accepted by food agencies, like the US FDA. But supermarket chains usually require higher certifications level (ISO, BRC or IFS) therefore cricket flour manufacturer are expected to raise their certification level soon, otherwise their customers - the PPIs makers won't be able to access mainstream food retailers. 9 of the companies interviewed derive their product certification from the co-packer, and only one has the lowest level of certification (GMP).

Even when having Internationally recognised safety certifications, PPIs may face great difficulties with food regulations in the world, in terms of clearing customs or being sold on the market. Regulations about insects as food differ widely (or are simply absent) in most countries. The topic is too complex to be discussed in detail in this article, but has been treated extensively elsewhere (Shockley et al., 2017, and for the European Union situation, Reverberi, $2020 \mathrm{~b})$. It should be noted that regulations are one of the critical barriers to PPI. For example, in the EU and (with the exception of silkworms) in China insects are considered novel foods subject to a long, expensive approval process. Crickets and mealworms are also absent from the United Nations FAO Codex Alimentarius where food standards are set internationally. Both the FAO and the WCO would require a member state to initiate the lengthy process of adding such a new category. As of 2018 no such request has been registered and therefore it may be years before any insect-related customs and safety standards are set globally.

\section{The bias about eating insects}

Several explanations for the Western bias against eating insects have been offered, some connected to the perception of insects as pests and the cause of agricultural damage. Also, insects in tropical areas are larger and easier to harvest (Van Huis, 2013), while livestock like cattle prefers a colder climate, which may be an additional economical difference between the two areas. But most of the reasoning revolves around psychological and emotional factors. In particular, food neophobia - the fear for unfamiliar foods - which is an innate human reaction against potential physical hazards. According to some authors (Baker et al., 2018; Verbeke, 2014) this might be the most critical barrier to edible insect acceptance.

The distaste towards insect eating sounds like a contradiction, as Western people don't know what an insect taste like. It is clearly challenging for PPI makers fighting against a preconception with little rational basis. They must convince consumers that the taste of the products is good, while consumers often perceive it as bad, not because it is, but because the food taboo translates into a taste preconception.

Luckily, a few recent analysis of the problem include the distinction between whole insects and processed products, and they focus on Western countries, including Germany (Orsi et al., 2019), the United States (Baker et al., 2018), and Italy (Cicatiello et al., 2016). These recent studies can help PPI makers' to make good product development and marketing choices. Simply pointing out that many non-Western populations have always eaten insects won't help much in convincing Europeans and North American consumers to try edible insect products (Deroy et al., 2015).

\section{Conclusions}

In order to correctly frame the new food products made with insects as an ingredient, a new category has been used in this research: packaged processed insects or PPI. About ten years after the first products appeared on the market, PPIs have generated a wide media coverage, but they are still not mainstream in terms of sales and 
presence in supermarkets and the makers are still quite small companies.

On the other hand, packaging has improved, some European retail chain are featuring PPIs on the shelves and the insect content percentage has increased, thanks to more affordable insect powder prices. The number of start-ups and the product variety has also grown. In the past few years Europe has also seen the raise of mealworm as ingredient and now many start-ups manufacture both mealworm - and cricket-based PPIs. Start-ups are targeting specific consumer groups (such as health - and fitnessconscious people and foodies) but in the interviews they affirmed they aim at a mass market in the future, thanks to PPIs main selling points: high nutrition and sustainability. Overcoming the regulatory obstacles and entering larger retail chains might be the next key step for the success of PPIs.

\section{Conflict of interest}

The author has a potential conflict of interest by being the founder of two edible insect start-ups (Plento and Bugsolutely). Products made by these companies may be in competition with other PPI. Plento and Bugsolutely are not among the companies interviewed for this article.

\section{Acknowledgements}

Anders Engström, insect bloggers and entrepreneur, offered guidance and valuable insights. His list of PPI products (https://www.bugburger.se/guide/the-big-listof-edible-insect-products) is constantly updated and a precious reference. Andrea Marianelli, F\&B consultant and nutritionist, conducted some of the interviews and provided precious feedback. Without the help of the PPI company founders who accepted to be interviewed writing this article would not have been possible.

\section{Supplementary material}

Supplementary material can be found online at https://doi. org/10.3920/JIFF2020.0111

Supplementary material S1. Short summary of the packaged processed insect (PPI) product makers who have answered the questionnaire.

\section{References}

Baker, M.A., Shin, J.T. and Kim, Y.W., 2018. Customer acceptance, barriers, and preferences in the U.S. Edible insects in sustainable food systems. Springer International Publishing, Berlin, Germany, pp. 387-399. https://doi.org/10.1007/978-3-319-74011-9
Canadian Food Business, 2020. Crickets: the gateway bug. Available at: https://canadianfoodbusiness.com/2020/02/11/crickets-thegateway-bug/

Cicatiello, C., De Rosa, B., Franco, S. and Lacetera, N., 2016. Consumer approach to insects as food: barriers and potential for consumption in Italy. British Food Journal 118(9): 2271-2286. https://doi. org/10.1108/BFJ-01-2016-0015

Collins, C., Vaskou, P. and Kountouris, Y., 2019. Insect food products in the western world: assessing the potential of a new 'green' market. Annals of the Entomological Society of America 112: 518-528. https://doi.org/10.1093/aesa/saz015

Deroy, O., Reade, B. and Spence, C., 2015. The insectivore's dilemma, and how to take the West out of it. Food Quality and Preference 44: 44-55. https://doi.org/10.1016/j.foodqual.2015.02.007

Dicke, M., Eilenberg, J., Falcao Salles, J., Jensen, A.B., Lecocq, A., Pijlman, G.P., Van Loon, J.J.A. and Van Oers, M.M., 2020. Edible insects unlikely to contribute to transmission of coronavirus SARSCoV-2. Journal of Insects as Food and Feed 6: 333-339. https://doi. org/10.3920/JIFF2020.0039

Dossey, A., Tatum, J. and McGill, W., 2016. Modern insect-based food industry: current status, insect processing technology, and recommendations moving forward. In: Dossey, A.T., MoralesRamos, J.A. and Guadalupe Rojas, M. (eds.) Insects as sustainable food ingredients: production, processing and food applications. Elsevier, New York, NY, USA, pp. 113-152.

Halloran, A., Flore, R., Vantomme, P. and Roos, N., 2018. Edible insects in sustainable food systems. Springer, Berlin, Germany. https://doi. org/10.1007/978-3-319-74011-9

Halloran, A., Hanboonsong, Y., Roos, N. and Bruun, S., 2017. Life cycle assessment of cricket farming in north-eastern Thailand. Journal of Cleaner Production 156: 83-94. https://doi.org/10.1016/j. jclepro.2017.04.017

Hanboonsong, Y., Jamjanya, T. and Durst, P., 2013. Six-legged livestock: edible insect farming, collection and marketing in Thailand. FAO Regional Office for Asia and the Pacific, Bangkok, Thailand. Available at: http://www.fao.org/3/i3246e/i3246e.pdf

IFIC Foundation, 2019. 2019 food \& health survey. Available at: https:// foodinsight.org/2019-food-and-health-survey

International Platform of Insects for Food and Feed (IPIFF), 2020. Questionnaire on the EU market. IPIFF, Brussels, Belgium. Available at: https://ipiff.org/wp-content/uploads/2020/06/10-06-2020-IPIFFedible-insects-market-factsheet.pdf

Lensvelt, E. and Steenbekkers, L., 2014. Exploring consumer acceptance of entomophagy: a survey and experiment in Australia and the Netherlands. Ecology of Food and Nutrition 53: 543-561. https:// doi.org/10.1080/03670244.2013.879865

Meticulous Research, 2019. Edible insects market - global opportunity analysis and industry forecast. Available at: https://www. meticulousresearch.com/product/edible-insects-market-forecast/

Muller, A., 2019. Insects as food in Laos and Thailand - a case of 'westernisation'? Journal of Social Science 47: 204-223. https://doi. org/10.1163/15685314-04702003

Nielsen, 2019. Sustainable food products on the rise. Available at: https://www.meatpoultry.com/articles/20722-nielsen-sustainablefood-products-on-the-rise 
O'Donoughue, A., Jennings, W. and Ahn, S., 2020. Finding and using a co-packer. University of Florida, Gainesville, FL, USA. https:// doi.org/10.32473/edis-fs380-2020

Orsi, L., Voege, L.L., Stranieri, S., 2019. Eating edible insects as sustainable food? Exploring the determinants of consumer acceptance in Germany. Food Research International 125: 108573. https://doi.org/10.1016/j.foodres.2019.108573

Pener, M., 2016. Allergy to crickets: a review. Journal of Orthoptera Research 25: 91-95. https://doi.org/10.1665/034.025.0208

Pippinato, L., Gasco, L., Di Vita, G. and Mancuso, T., 2020. Current scenario in the European edible-insect industry: a preliminary study. Journal of Insects as Food and Feed 6: 371-381. https://doi. org/10.3920/JIFF2020.0008

Pothering, J., 2019. Protifarm raises Series B to scale robot-grown beetle 'tofu'. AgFunderNews. Available at: https://agfundernews.com/ protifarm-raises-series-b-to-scale-robotized-beetle-tofu-farm.html

Reverberi, M., 2020a. Edible insects: cricket farming and processing as an emerging market. Journal of Insects as Food and Feed 6: 211220. https://doi.org/10.3920/JIFF2019.0052

Reverberi, M., 2020b. Current EU novel food regulation. Bugsolutely Blog, Bangkok, Thailand. Available at: https://www.bugsolutely. com/novelfood/

Ruby, M.B., 2012. Vegetarianism. A blossoming field of study. Appetite 58: 141-150. https://doi.org/10.1016/j.appet.2011.09.01

Schiemer, C., Halloran, A., Jespersen, K. and Kaukua, P., 2018. Marketing insects: superfood or solution-food? Edible insects in sustainable food systems. Springer, Berlin, Germany. https://doi. org/10.1007/978-3-319-74011-9_14
Shockley, M., Allan, R.N. and Gracer, D., 2017. Product development and promotion. In: Van Huis, A. and Tomberlin, J.K. (eds.) Insects as food and feed: from production to consumption. Wageningen Academic Publishers, Wageningen, the Netherlands.

Van Huis, A., Van Itterbeeck, J., Klunder, H., Mertens, E., Halloran, A., Muir, G. and Vantomme, P., 2013. Edible insects: future prospects for food and feed security. FAO Forestry Paper 171. FAO, Rome, Italy, pp. 35-43. Available at: http://www.fao.org/docrep/018/i3253e/ i3253e.pdf

Verbeke, W., 2014. Profiling consumers who are ready to adopt insects as a meat substitute in a Western society. Food Quality and Preference 39: 147-155. https://doi.org/10.1016/j.foodqual.2014.07.008

Videbaek, P. and Grunert, K., 2020. Disgusting or delicious? Examining attitudinal ambivalence towards entomophagy among Danish consumers. Food Quality and Preference 83: 103913. https://doi. org/10.1016/j.foodqual.2020.103913

Weigel, T., Fèvre, S., Berti, P.R., Sychareun, V., Thammavongsa, V., Dobson, E. and Kongmanila, D., 2018. The impact of small-scale cricket farming on household nutrition in Laos. Journal of Insects as Food and Feed 4: 89-99. https://doi.org/10.3920/JIFF2017.0005 Wendin, K., Norman, C., Forsberg, S., Langton, M., Davidsson, F., Josell, Å., Prim, M. and Berg, J., 2017. Eat 'em or not? Insects as a culinary delicacy. In: Proceedings of the $10^{\text {th }}$ International Conference on Culinary Arts and Sciences, July 5-7, 2017, Copenhagen, Denmark. 